\title{
Literature in New Media: A Comparative Study of Literary Affordances of Lance Olsen's “10:o1” in Traditional and Digital Medium
}

\author{
R.Ramya ${ }^{1}$ and Dr.Rukmini.S ${ }^{2}$ \\ ${ }^{1}$ PhD Scholar, Department of English, School of Social Sciences and Languages, VIT, \\ Vellore. ORCID id: oooo-0oo2-7298-5959. Email: ramyarajakannan7@gmail.com \\ ${ }^{2}$ Senior Assistant Professor, Department of English, School of Social Sciences and \\ Languages, VIT, Vellore. ORCID id: oooo-ooo1-8414-3145. \\ Email:rukminikrishna123@gmail.com
}

\begin{abstract}
The recent advances of the digital era invoke an array of new media for communication. This impressive feat of technology purveys a wide range of new affordances to communication unviable in print. The new media affordances of the electronic and the digital have impacted the creative literary compositions, providing innovations in contemporary literature. Postmodern literature being the initiation of experimental works has strived to reinvent the affordances of literary fiction. It has now advanced into resorting to digital technological affordances to maximize narrative inventiveness. Lance Olsen's "10:01", a postmodern novel adapted as hypertext fiction, is an exemplar of such feat. This research examines the literary affordances of the chosen text in print and its hypertext adaptation within the framework of affordance theories. The study unveils the inlaid new media aesthetics and viabilities of the digital in relation to the traditional medium of print by focusing on affordances. The paper asserts the significance of theorizing the aesthetics involved in digital textuality by holding print and electronic literature at the intersection. This study aims to establish the shift in literary analysis paradigms of text due to the emergence of New media.
\end{abstract}

Keywords: Electronic literature, New media, Literary Affordances, Print vs Digital, Hypertext fiction, Postmodern Literature, New media Aesthetics.

\section{Introduction}

The origins of literacy remains a conundrum, for it is a process and product of writing. The history of writing is inaccessible, for it rests with the human race that walked the contours of earth where speech and physical actions were the only medium of communication. However, general speculation points to writing as a mode of recording the burgeoning information in new cooperative systems of civilizations, traced back to 3500 BCE. Till today writing endures as the greatest invention in the history of the sapiens, not as a mere skill but a revolutionary technology that redirected human history as it restructured human consciousness to perceive, read and write utterances turned into visual symbols. Writing steadily ameliorated with technological updates, and now it is at the frontiers of digital headway into machine learning and artificial intelligence.

(c) AesthetixMS 2021. This Open Access article is published under a Creative Commons Attribution Non-Commercial 4.0 International License (http://creativecommons.org/licenses/by-nc/4.o/), which permits non-commercial re-use, distribution, and reproduction in any medium, provided the original work is properly cited. For citation use the DOI. For commercial re-use, please contact editor@rupkatha.com. 
(Coover, 1992) in his essay "The End of Books", proclaims, "there have been three great events in the history of literacy: the invention of writing, the invention of movable type and the invention of hypertext." The history of literacy changed with these significant inventions. Writing eliminated orality and established print that is now receding due to digitality. The rise of novel is a consequence of print, raising debate of copyright that caused a shift in the focus of critique from the press to text, hence to the author, until modernism and the succeeding postmodernism.

The $2 \mathrm{O}^{\text {th }}$ century marked the onset of digital technology, salient with proclamations on the death of many preceding technologies and concepts: [the death of] author, book, novel and the print medium. The word 'death' here also implies the shift of focus to the medium we have been oblivious to for ages. Marshall McLuhan is the first to bring our attention to the medium with his lynchpin coinage, "the medium is the message". The postmodern literature succinctly tries to draw the readers' attention to these new media by embedding elements from other media and genres to experiment with the affordances of print and upgrade text from linear, author-dictated medium to a reader-centred interactive medium of creative imagination. In today's world of multifaceted entertainment goodies, print-based literature is deteriorating at a steady rate. When Vannevar Bush and Ted Nelson envisioned an all-knowledge incorporating hypertextual realm, they stretched the limits of any communication medium's affordances, resulting in the creation of the World Wide Web.

'Hypertext' being characteristic of Roland Barthes' lexia- refer to "units of reading” with which plural texts are analyzed, facilitating a ceaseless embedding of texts within texts. The $21^{\text {st }}$ century literatus are determined to create interactive systems that allow greater scope for polyvocal, nonlinear, hypermedial tales, especially hypertext fictions. Robert Coover announces the death of books in 1992; he vouches for the scope of new dimensions in literature. However, the hypertext fictions did not gain the momentum and popularity as expected. Different researches discuss the medium as a cul-de-sac or emphasize reader-centricity.

Lance Olsen, an American writer, is known for his experimental postmodern oeuvre. He authored 15 novels, 5 nonfiction, 5 short story collections, a poetry collection, all being sceptical of human accumulated knowledge. 10.01 (2005) is his only hypermedia text that exists as print text. It aims to attain a convergence between print and the digital, paving the way for future transmedia approaches pursued by postmodernists. Olsen published both versions simultaneously with the help of Timothy Sean Guthrie-a visual artist and an American filmmaker-experimenting with the affordances of both media. This study shows how Olsen exploits the affordances of digital hypertexts and print to elevate his postmodern narrative composition. This paper utilizes close reading and media analysis to bring out the affordances of both these media and highlights how they supplement the postmodern experience of this narrative text. This study attempts to understand and elicit the affordances of both media as utilized by Olsen to shape his literary work. The text chosen is unique in its approach to writing fiction. This paper tries to draw out Olsen's unique experiments with these two media of choice.

\section{The Media is the Matter}

Marshall McLuhan is the crucial media theorist who initiated the discourse on the medium that contains the matter and its effect on our perception. He points out the imperative of media studies by observing how "the content of any medium is always another medium". He proposed a tetrad of 
media effects in his work Laws of Media (1988)—where he assesses the figure(medium) and ground (context) properties of media, namely, Enhancement and Retrieval [and] Obsolescences and Reversal. To apply this to any medium, he also proposes four questions that the tetrad stands for:

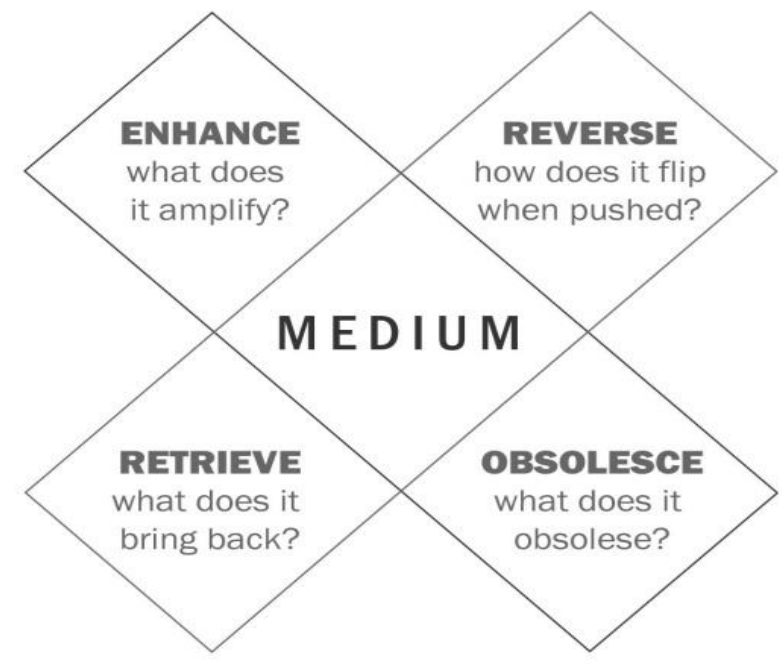

Tetrad of Media Effects
McLuhan (1988)

Figure 1. Marshall McLuhan's Tetrad of Media Effects (1988)

1. What does the medium enhance?

2. What does the medium make obsolete?

3. What does the medium retrieve that had been obsolesced earlier?

4. What does the medium flip into when pushed to extremes?

The theory of affordances developed alongside media theories and other significant theories the emerged in the $20^{\text {th }}$ century. However, these theories lacked impetus until the age of digital technologies. Affordance "is the properties of an object that allows it to function". James .J. Gibson initiated the discourse on affordances in "The Theory of Affordances" (1977). As all objects are identified with their function, Donald Norman in 1988 elaborated on the affordance theory, and he devise a palpable perspective, including the forthcoming media of ICT. Norman introduced "perceived affordance" and redefined affordance as "action possibilities", stating that perceived actions are distinct from possible actions that propagate an inconsistent meaning which depends on the user identifying the function and perform the action intended:

“...the term affordance refers to the perceived and actual properties of the thing, primarily those fundamental properties that determine just how the thing could possibly be used. [...] Affordances provide strong clues to the operations of things. Plates are for pushing. Knobs are for turning. Slots are for inserting things into. Balls are for throwing or bouncing. When affordances are taken advantage of, the user knows what to do just by looking: no picture, label, or instruction needed." (Norman, 1988, p. 9)

(Gaver, 1991 ) classified affordances under three categories that made the theory achieve its full potential:

1) False Affordance- action is not possible but perceivable.

2) Hidden Affordance- action is possible without cues. 
3) Perceptible Affordance- action possibilities.

4) Correct Rejection- no action or perception is possible.

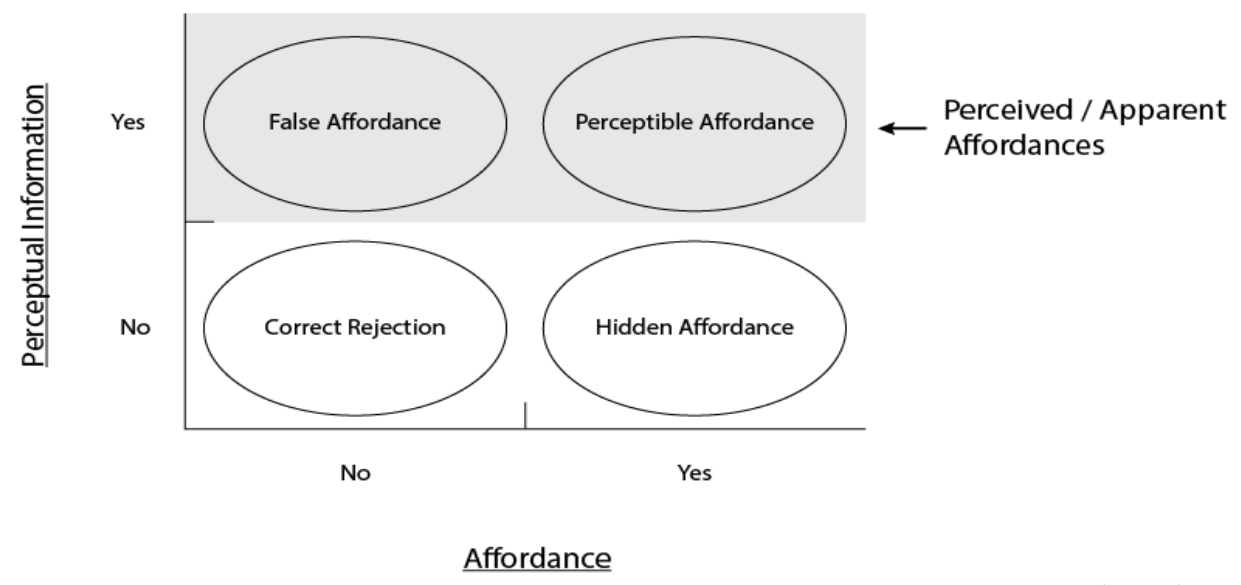

Figure 2: Classification of 'Affordances' adapted by Gaver (1991)

Studying the affordances can explain the perceptive of objects and possibilities, which may be false, hidden or perceptible. Affordance allows free-play as well as the directive. Applying this theory to experimental literature of modern and postmodern will open a new array to understand how the content of these texts are composed and presented to the readers.

Ever since the modernist movement, the literary enterprise went avant-garde. With their counter-traditional experiments, postmodernist literary compositions used mass cultural media models in their writing as a reaction to "high art". As a result, their inclusive, nonlinear, chaotic works are abundant with characteristics of advanced media societies such as reflexivity, metafiction, self-referentiality, intertextuality, hybridity, induced focus on the perceivable surface rather than depth, images and copy, reality and originality.

\section{10.o1's Affordances in Print}

Books are the consequence of writing. The manuscripts of the old ages had different ways of penning the content. The print standardized the writing space as a medium of speech. (Kirschenbaum), one of the pioneers of digital studies listed five affordances of books:

1. Random Access and Sequential- books allow both random and sequential access to its content, but most contents are represented linearly.

2. Volumetric- Books are three-dimensional artefacts with height, width, depth and weight.

3. Bounded-Books are bounded together.

4. Comparative- Books represent its content in a comparative visual space from left to the right on pages.

5. Writeable - Books are readable and writeable.

Books have been a stagnant technology with no possible upgrades for centuries. Nevertheless, the impact of the latest technologies contributes to redefining the literary traditions 
and ergodicity of the books in terms of conceiving the texts and decoding the message. The Internet became an inevitable tool of the meaning-making process, which enabled the convergence of the analogue with the digital. However, postmodern books push the boundaries of the conventional writing space by exploiting their rearrangeable affordances.

10.01 has prominent new media features making it a salad bowl of a series of micro-narratives encased within 10 minutes and 1 second about random audience sitting in the Mall of America watching the commercials before the movie is screened. The novel extends beyond the general conventions of a traditional novel with its experimentation with textuality. The following are text reconfiguring principle employed in the novel to achieve innovation in fiction.

\subsection{Random access actualizes non-linearity}

The novel rejects the traditional poetics of hierarchized characterization with the introduction of micro-narratives. The narrative reveals random thoughts of the random characters from different ethnic and cultural background. There are 105 micro-narratives in this novel activating the random access affordance of print. In each chapter, an omniscient narration of thoughts and events occur, occurred or will occur in the life of a character/s. With random access, the book is accessible to experimentation. Since the narrative time is only ten minutes and each page is a micro-narrative. Olsen's use of micro-narratives enacts Lyotard's definition of postmodernity of "incredulity towards metanarratives"-a totalizing legitimacy propagated metadiscourses and ideologies - to replace the grand narratives of enlightenment with 'little narratives' or micronarratives/ petits récits: a localized representation of restricted domains. Olsen replaces traditional mimetic autonomy of story worlds, which focuses on a single character with a multicultural myriad of characters. With this, he actualizes the collapse of grand narrative to capture the readers' attention to the postmodern abundance of micronarratives and the significance of its representation in fiction to reconfigure the poesies of creative fiction.

\subsection{De-volumizing Narrative Aesthetics}

The novel is spacious despite the garrulous cacophony of the micro-narratives. The author aesthetically downsizes the poetics of the traditional novel by referencing the weight of lives carried within 10 minutes and the insignificance of the same by reducing a person's life to a mere skippable description. He uses sentence numbers, fragmented description, and film scripts to achieve this. The author leaves almost all pages half-blank and uses time signatures instead of chapter titles. The page numbers are displaced by the time markers, which serve as actual page numbers. The halfempty pages and the descriptions, and the time frame, accomplish a de-volumizing effect on the space and time in the novel. It remediates normalized order of word arrangements:

the pages in this novel, by disrupting that order create a spatial unit that does not intend to erase itself. So . . the changes in fonts and word arrangements in the . . . arrangement of words on every page show diverse characters that the novel depicts. ( Mehdy and Payam, 2014, p. 151 )

The narrative time, fragmentation, self-reflexivity, contingency of the tense (present tense mainly) makes the reader aware of its new metatextual affordances. Therefore, it aesthetically reduces the density of emplotment as each section is a non-hierarchized character description and enriches the narrative possibilities of a book. 


\subsection{Camera Narrator}

The text assimilates visual storytelling techniques into its composition. The narration is omniscient but dramatized with an on-screen camera action translated into writing. As shown by a camera the story reads, the compilation of scenes broken into segments or pieces- "a collection of camera shots that are subsequently edited and fit together to create that seamless "moment of time" (Lakin, 2016). In Architectures of Possibility: After Innovative Writing,

Olsen charts literary/artistic possibilities for approaching creativity that speaks to the reality of the twenty-first century. Returning to the idea of the Difficult Imagination, he wants writing to be a "possibility space where everything can and should be considered, attempted, and troubled." Seeing writers as existing in particular "space and time," Olsen asks how each of these writers "might most effectively capture that place and point in [her] own writing." (Olsen, 2012, as cited in Hogue,2012)

Olsen effectively captures the space of theatre in narrative fiction. The randomness of scenes coincides randomly with characters causing random encounters as in everyday lives. The viewpoint is objective with a video-like narration of events montaged in time where each section is an event in a frame of time.

The narration in the novel begins at oo.oo.oo.oo with Kate Frazey; it gets crowded with multiple characters at different but narrowly displaced time signatures. The story is drafted mimicking the movie scene shot with the camera. The author uses mise-en-scene ("the action of putting onto the stage") instead of mise-en-abyme ("story within the story") in the construction of the plot. The naturalistic mise-en-scene technique is employed in each micronarrative, describing the character's placement concerning the other nearby characters, the costumes, the seating arrangement in a single setting. The frame of references slides on from one character to another in vignettes similar to camera shots in filmmaking. The author introduces a new approach to narration in this fashion by incorporating and mimicking the potential affordances of the camera into the linguistic, textual representation of the novel.

\subsection{Unbounded Rhapsody}

Walter J. Ong, in his commendable work Orality and Literacy (1982), remarks “orally based thought and expression are additive rather than subordinative; aggregative rather than analytic; redundant, conservative, close to the human lifeworld, agonistically toned, empathetic and participatory rather than objectively distanced; homeostatic and situational rather than abstract". (Ong, 1982, as cited in Gibert, 2006)

The narration 10.01 resembles watching a movie on a player and does not converge into a single unity. Nonetheless, it produces a narrative that is inclusive, allowing any number of tales to be spliced into the text. The text is simultaneously aggregative and analytic, as it is a fully captured representation of a specific time frame within a particular place of the human world. It achieves objectivity through omniscient narration and interactivity with its random access narrative principles. On certain pages, the narrative reads more like flash fiction:

"oo:08:35:06

Kosa Prcac's ghost darts left, into and out of her husband's mind, the passing impression being one of flying extremely fast through a silver haze of sunshine." (Olsen, 2005, p. 147)

The reader is left hanging without further explication compelling the readers to participate and fill the gaps. The captured instance of the human world is as alive and in motion as in a moving picture, rather than being frozen like a photograph. This brings back the age-old tradition of orality that allows "stitching together" (rhapsody) of varied narratives. It is signified in its hypertextual 
reference to 1001 Arabian Nights that carries within traces of orality even in its written adaptation. Olsen's narrative resembles oral freedom and seamless inclusion of infinite stories stitched together with alterable narrative sequences and violates the bounded principle of the book. This accomplishes a convergence and sustainable symbiosis between the oral and linguistic aspects.

\subsection{Different Writing Styles and Typefaces}

Olsen uses different writing styles and typefaces in each of the micronarratives, for instance: Italics for the inner train of thought: ". . .just the way she smells, peppermint shampoo, just these things, just these and nothing more, just here, just like this, just my fingertips moving" (Olsen, 2005, p. 7. ).

At 0o.00.06.23, the narrative description of Lydia Larrabee (a little girl) is narrated without a full stop. Stuart Navidson's reference to the refrigerator magnets: "PUPPET OPENS RED DOOR UPON WOLF SKY to WOLF PUPPET OPENS SKY DOOR UPON RED” (p.30) is fully capitalized.

Cynthia Morgenstern's narrative is written in numbered sentences:

“1. Cynthia Morgenstern, one seat behind and right of Jerry Roemer, wants to love Cary Grant, only in black and white. . 15. It is dark. Remain calm. This will all be over soon." (pp. 62-63).

At 00.04.57.04, the entire section is written in the form of a film script:

EXT. MALL OF AMERICA-DAY

CRANE SHOT: swim in slowly through an insane blizzard. South entrance of the Mall of America gradually resolves into focus. . . dismal day.

CELAN'S THEME—a soft, sad, fluid Philip Glassian piece—rises on the soundtrack.

The camera chooses one of the bundled pedestrians and unhurriedly swoops through the entrance over his/ her shoulder.

\section{CUT TO:}

\section{INT. MALL OF AMERICA-DAY (pp. 77-78)}

Pastiche is typical of postmodern intertextuality. It entails "pasting together" varied elements to create a parody. This inclusion of the people's dialects and idiolects as linguistic representation, on the other hand, is a marker for diversity in people, cultures, and characterisation. Most significantly, it is additional attempt to broaden and experiment with a new scope of print by creating novel-wide representations of other media.

\subsection{Hyperreality}

(Baudrillard, 1981) formulated hyperreality as a theory of representation claiming nothing exists outside representation. It is a critique of media reproduction formulated in his seminal work Simulacra and Simulation (1981). The image-based postmodern communication technologies are denoted as the causatum of the disappearance of meaning and inertia of exhaustion, where everything is obscenely on display. Hyperreality is the process where representation replaces the real. 
The epigraph in the novel, which consists of Walt Whitman's quote from Leave of Grass, "- you must habit yourself to the dazzle of the light" (Olsen, 2005) and cover with a black and white image of a man's silhouette facing opposite to the camera demonstrates the balance between black and white. Our perception is shrouded with the tinted filter of copies with the theatre and visual media flooding people with a depthless world of unreflecting images. The movie signifies the 'Plato's "Allegory of the Cave" which suggests that human tend to live entire lives in the darkness of the cave, illusion our perceptions when the true knowledge is obtained only through intellectual inquiry. "For the postmodernist, the intellectual process is deconstruction and critical thought, and the utopia is the multicultural but radically individualistic world, and the replacement of capitalism" (The Death of Postmodernism and Beyond, 2018). The half blank pages and gathering myriad of other innovative narrative principles signify the need to get habituated to the dazzling light of the actual world than staggering in the darkness of the representations of reality in the capitalist world of consumerism. The narrative in capturing the ten minutes of the advertisement reels before the screening of the movie illustrates our oblivious lives in the shadows of representations.

Olsen illustrates the fact that traditional books can extend beyond their inherent features. Still, the uniformity ascribed to print for general ease in perception tends to preoccupy the novelists and writers, clouding the hidden affordances of the print media. By visually drawing the reader's attention to the medium of print and its undiscovered affordances, the author purposefully draws our attention to the hidden affordances of print.

\subsection{0.o1's Affordances in Hypertext Medium}

The digital version of 10.01 created along with Tim Guthrie is hypermedial with an array of visual and written affordances with elements of hybridity such as sounds, graphic designs, animations with different modes of communication, "Manovich calls this property modularity, such as the characteristic of media objects to be composed of small parts with their own autonomy as in a 'fractal structure"' (Venditti et al., 2017). This HTML version developed using Flash, enhances its fluidity and facilities the linguistic comprehension of textual components. "As the material aspect of a book affects how readers experience a narrative, allowing them to unfold the story one page after another, so the [hypertext]as the form of contemporary communication. . .determine how users perceive and interact with narratives through the medium affordances" (Venditti et al., 2017). This adaptation elevates the action of experience with its hybridized new digital form.

In the introduction marquee, we find epigraphs from other sources, different from the print version.

"Film can be exploited for a certain time as a scientific curiosity, but apart from that, it has no commercial value whatsoever". - Auguste Lumiere (1895)

"Francine: What are they doing? Why do they come here?

Stephen: It's some kind of instinct. Memory. What they used to do. This was an important place in their lives". M-George Romero, Dawn of the Dead

Let us say Wendy's is an airplane. Travelling at ten thousand feet. Let's say there's no landing gear and nowhere to land, And fuel is limited. And one has a general idea of when the fuel is going to run out. Given this knowledge, is travel really the right word? And if not travel, 
then what? One sees one's life quite differently when one knows it isn't going to land.-Joe Wenderoth, Letters to Wendy's (10.01, 2)

The difference in epigraphs from the print version invites us to the apparent new media and its affordances. Digital and hypertext fiction was perceived as a medium with the revolutionary potential to redefine literary compositions:

Hypertexts permit reading texts with advanced features like "enhanced functionality, customized views and improved knowledge synthesis and representation." Given the multiple choices in the narrative, the readers get a God-like power to control the narrative that the author is writing. Hypertext extends Robert Brooke's postmodern critique across another dimension: not only must the author be out of control of his or her creative processes, but the author can no longer control the way the reader navigate through the text, or even the order of the contents of the text itself. (Sarkar, 2020)

Howsoever, it did not acclaim the popularity that was expected of it. Nevertheless, the quotes suggest it is too early to determine the success or failure of this medium. With the increase of consumerism, we live in a world where the media are the most significant mass media contributors, digital communications 'fuels' consumerism. The final quote is an indirect reference to the affordances of digital fiction, which beyond traditional print fictions and the changing readership with no definite dictates to the reading process where one does not know the course of reading.

\section{1 Affordances of Hypertext Version}

This section explores the different affordances of the digital version of the novel. It uses Classification of 'Affordances' adapted by Gaver (1991) to study the digital affordances of the hypertext medium with respect to the chosen work. The following image shows some of the perceptible affordances of this version of the text.

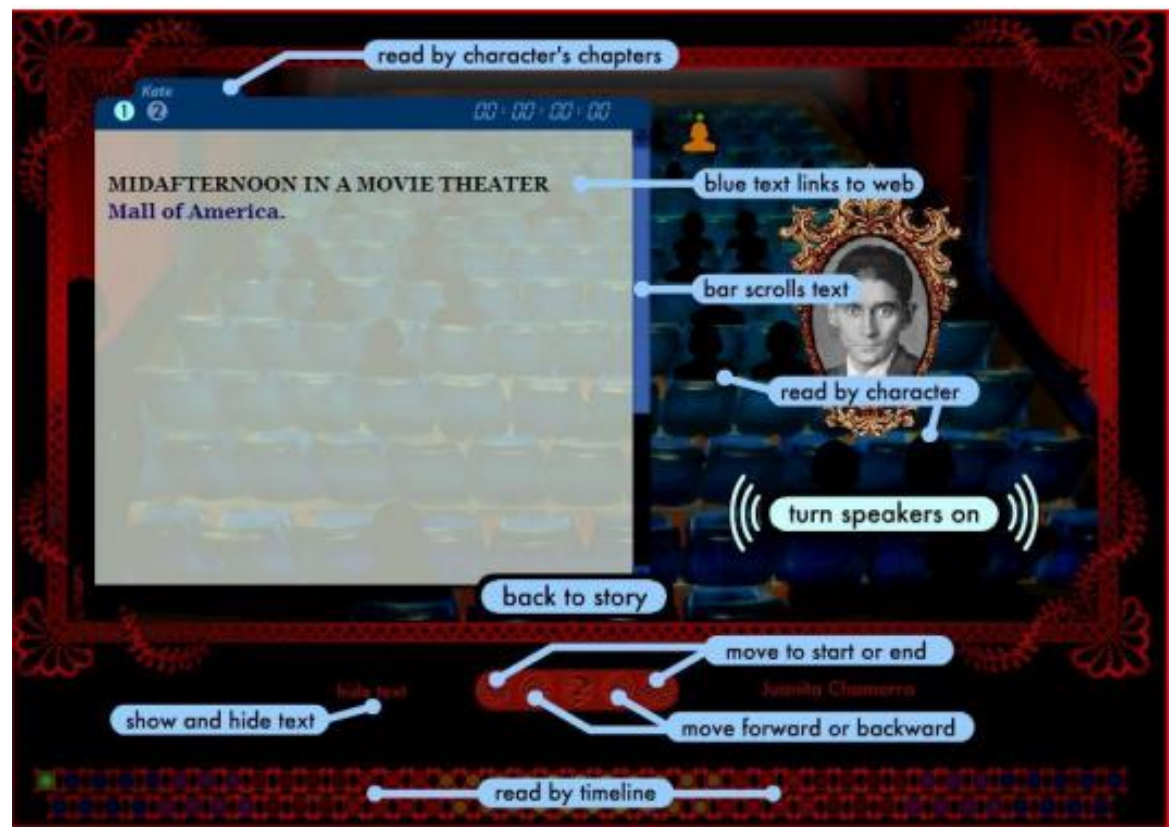

Figure 3: Opening Interface of Lance Olsen and Tim Guthrie's 10.o1 


\subsubsection{Perceptible Affordances}

a) Navigation nodes: Unlike printed novels, the postmodern non-linearity can be achieved with the navigation buttons as shown in the picture, the readers are invited to "read by character's chapters" as in the book, the same is possible with the "start or end" and "forward or backward" buttons. However, the text can also be "read by characters" seated in the chairs; this allows total non-linearity with no beginning, middle or end. Each of these nodes are embedded in between, making it possible to initiate infinite possible paths for the readers.

b) Visual components: The hypertext version paints a visual image of the theatre and audience sitting in their seats. Digital fiction is also rich with several visual images, which can be accessed by hovering over the hyperlinks that display paintings of the objects signified in the blue hyperlinks embedded within the text. At the head of the display, there is a steady flickering of the commercials screened before the commencement of the movie resembling the theatre screen. Unlike the book version, the hypertext version allows the inclusion of visual elements that contribute to the narrative similar to literary devices enabling Olsen's desire to capture events at a specific point of time.

c) Sonic elements: This version also has audio elements corresponding to the visual and character descriptions. The story looks alive and offers better visual, sonic registers to understand and remember the diversity encoded into the narrative. The non-linearity pushes readers into cognitive dizzy. The visual and sonic aspect, on the other hand, draws readers back into reading process and offers visual and aural markers that help readers recall character's location and descriptions. They act as visual cues for the reader's act of reading and enrich the reading/navigating experience.

d) Textboxes: With the clicking of each button, pops open a text box with the novel's content relating to each of the characters. The Green light on the character's head indicates the position of the character. The textboxes actualize the randomness micronarratives for enabling non-linearity since the readers are conditioned for linear navigation, but "reading works of eLiterature requires an additional nontrivial effort to traverse the text, an effort Espen Aaeseth defined as ergodic" (Fabio). As a result, readers are compelled to make their own navigational choices.

\subsubsection{Hidden Affordances}

a) Interactivity: The $2 \mathrm{o}^{\text {th }}$-century discourse on fiction moved from analysis of form to semantic and then to the reader. In the last decades of the $20^{\text {th }}$ century, authors strived to create reader-centric literature. This technique resulted in the incorporation of trans-textual concepts into print fiction. The physical act of clicking provides the reader with the power of choice, achieving Roland Barthes' dream of lexia, which the writers pursue by incorporating interactivity into narrative fiction. Hypertext fictions enable the authors to activate interactivity in storytelling. Although it is a new feat in postmodern literary compositions, the affordances of hypertext fictions allow a veritable upgrade to literary compositions unavailable in print.

b) Polyvocality: is the use of multiple voices to shift and sustain narrative change. Hypertext is a "radically divergent technology, interactive and polyvocal, favouring a plurality of discourses over definitive utterance and freeing the reader from domination by the author" (Coover, 1992). The text accentuates plurality and denounces grand narratives on perfect human personalities. It also demonstrates how multi-vocalism is accomplished through the use of visual elements that contribute to the narrative. The nonlinear interactivity also achieves polyvocality of the reader's 
point of views where each reader has his/her path through the narrative. It attempts to display the inevitable plurality of voices heavily populated with numerous media for communication.

c) Reader-centric: The reader being able to choose his path via the networked nodes allows the readers to participate with the narrative and involve with the process of emplotment. "According to Bell, even as hypertext fiction locks the reader out of the ancient amusements of straightforward storytelling, it stirs up a countervailing labour action, an arguably novel concern with language as a system: The reader is always aware that the current reading path can be replaced by an alternative so that it is apparent that it is only ever a temporary construction" (Moulthrop, 2012). The plot is a significant contribution to the poesies of fiction. The affordances of hypertext medium free the text from the long tradition of author dictated narratives and activate a participatory reading affordance.

\subsubsection{False Affordances}

a) Immersive narration: The fluidity of narration with nonlinear hyperlinks was intended to create engaging and immersive narratives that are reader inclusive. However, the readers often complain about the hyperlinks causing distractions more than immersion.

b) Author-dictate free: The hypertexts claim to be a medium that is free of author dictates, but the hypertext fiction is not entirely reader-centred as the links are not fully randomized. The author has partial control over the structure of the code and output of the display. The paths are multiple, but the nodes are limited.

\subsubsection{Correct Rejection}

Hypertext fiction is not as immersive as video games or augmented virtual reality. In the postpostmodern age, digital intervention has created limitless entertainment goodies. The hypertext fictions have failed to create an immersive fictional world spurring a popular attraction. Despite the medium's unlimited potential, it failed to capture the reader's interest owing to a lack of additional experimentation with its affordances and the difficulties in narrativization. The digital text can accomplish much more than a physical book. The affordances of digital texts allow enhancement of trans-textual possibilities expanding the scope of new arrays and feats in critical approaches to literature. The structure, textuality, visual, sonic elements and animations configure together as a literary text. The transmission units arise from the medium's affordances, which must be considered in critical text analysis.

\section{Conclusion}

Annihilation is embedded within birth; Olsen wisely eliminates claims of death in the novel and demonstrates the emulations of the old with the new dynamics of media. "In an interview in Chiasmus, Lance Olsen argues that mimetic fiction (the linear model) as a genre has been naturalized and that innovative fiction, which has always existed marginally alongside conventional fiction, is the real realism today." hence "Olsen de-naturalizes mimetic fiction and offers innovative fiction as the way to represent life/existence in the twenty-first century" (Hogue, 2012, p.27). 10.01 by Lance Olsen draw parallels between the print and hypertext to compare and converge the two media as well as hold their affordances at their section. In doing so, he assimilates a simultaneous hybridization of both the media drawing our attention to the inadequacy of creativity in narrative fiction through the medium of books. It provides solution with his experimental writing and underscores the need for innovation in reflecting lived experiences through the narratives. 
Applying Marshall McLuhan's 'Tetrad of Media Effects' to hypertext mediums to measure the possible prospects and effect, we find:

1. What does the medium enhance?

Hypertext, an upgrade of the print has perceptible new affordances. It enhances inclusive hypermediality and visual narrative principles.

2.What does the medium make obsolete?

Though hypertext is a viable upgrade of print's linguistic representation, it still occupies an inferior position compared to print and imitates the affordances of print.

3.What does the medium retrieve that had been obsolesced earlier?

The hypertext and postmodern approaches try to retrieve the lost assets of orality with the hypermedial visual and sonic elements, which Walter Ong calls secondary orality:

The electronic transformation of verbal expression has both deepened the commitment of the word to space initiated by writing and intensified by print and has brought consciousness to a new age of secondary orality. . . secondary orality generates a sense for groups immeasurably larger than those of primary oral culture-McLuhan's 'global village'.

(Ong, 2002)

4. What does the medium flip into when pushed to extremes?

Hypertexts are a relatively new technology that is currently being experimented. Therefore, it is too early to draw any conclusions, as it is not pushed to its threshold. Nevertheless, it has the potential to reinvent the process of reading and creative composition.

Olsen delineates the prospects of both medium in this work and demonstrates the unexplored affordances of print media in his print version. He does not oust the old media to glorify the new media, but he does emphasize the transmediality of a single work across different media. These emerging new media has the potential to rewrite, transcend and subvert literature hegemonies. This kind of creations opens new horizons for literature.

\section{References}

A brief history of literacy | UTA Online. (2015, September 9). UTA Online. https://academicpartnerships.uta.edu/articles/education/brief-history-ofliteracy.aspx\#: :text=In\%2ofact\%2C\%2oliteracy\%2ohas\%2oa,public\%2operformances\%2C\%2odisplayin g\%2otheir\%2oskill.

Coover, R. (2018). The End of Books. Nytimes.com. https://archive.nytimes.com/www.nytimes.com/books/98/o9/27/specials/coover-end.html

De, V., \& Fabio. (n.d.). eLiterature: Literature in the Digital Era. Definition, Concept and Status. https://eliteratures.files.wordpress.com/2011/05/de-vivo-fabio-intervento-ole-inglese.pdf

Donald .A., N. (1998). The Psychology of Everyday Things. New York, Basic Books.

Gibert, T. (2006). "Written orality in Thomas King's short fiction."

Journal of the Short Story in English. Les Cahiers de La Nouvelle, 47. https://doi.org/http://journals.openedition.org/jsse/792 
Grigar, D., Emerson, L., \& Berens, K. I. (2012). Curating the MLA 2012 "Electronic Literature" Exhibit. Rhizomes.net. http://www.rhizomes.net/issue24/grigar.html

Hogue, W. L. (2012). Reconfiguring the Textbook. American Book Review, 33(4), 27-28. https://doi.org/10.1353/abr.2012.0098

https://www.facebook.com/studiobinderapp. (2020, September 13). Mise-en-scene and the Directors the Mastered It. StudioBinder. https://www.studiobinder.com/blog/mise-en-scene/

Johnson, S. (2013, April 16). Why No One Clicked on the Great Hypertext Story.

Wired; WIRED. https://www.wired.com/2013/o4/hypertext/

Kirschenbaum, Matthew. Bookscapes: Modeling Books in Electronic Space.

Lakin, C. S. (2016, December 26). 6 Cinematic Techniques You Can Apply to Your Novel Right Now | Live Write Thrive. Live Write Thrive | Insights, Inspiration, and Practical Advice for Writers. https://www.livewritethrive.com/2016/12/26/6-cinematic-techniques-you-can-apply-to-your-novelright-now/

Mehdy, S., \& Payam. (2014). Metatextual Print Fiction in the Age of Digital Fiction.

https://researcharchive.vuw.ac.nz/xmlui/bitstream/handle/10063/8701/thesis.pdf?sequence=2

Moulthrop, S. (2012, January 31). For Thee: A Response to Alice Bell > electronic book review. Electronic Book Review > Digital Futures of Literature, Theory, Criticism, and the Arts. https://electronicbookreview.com/essay/for-thee-a-response-to-alice-bell/

Modir, L. (2015). A Comparative Study Of The Printed And Hypertext Novel 10:01 By Lance Olsen. Core.ac.uk. https://doi.org/oai:generic.eprints.org:29892/core423

Olsen, Lance. 10:01. Chiasmus Press, 2005.

Olsen, L., \& Gutherie, T. (2021). 10:01. Eliterature.org.

https://collection.eliterature.org/1/works/olsen_guthrie__10_o1.html

Ong, W. (2002). Orality and Literacy. https://monoskop.org/images/d/db/Ong_Walter_J_Orality_and_Literacy_2nd_ed.pdf

R., Ambra, J., Wilson, C., \& Akter, S. (2017). Affordance Theory and E-Books: Evaluating the E- reading Experience Using Netnography. https://ro.uow.edu.au/cgi/viewcontent.cgi?article=1560\&context=gsbpapers

Sarkar, J. (2020). Reading Hypertext as Cyborg: The Case of Patchwork Girl.

Rupkatha Journal on Interdisciplinary Studies in Humanities, 12(5). https://doi.org/10.21659/rupkatha.v12n5.riocis2n2

Schilf, M. (2010, January 22). Camera as Narrator - The Script Lab. The Script Lab. https://thescriptlab.com/screenplay/what-is-a-screenplay/37-camera-asnarrator/\#: :text=By\%2oMichael\%2oSchilfJanuary\%2022\%2C\%202010\%2oWhat\%2ois\%20a\%2oScreenpl ay\%3F\&text=A\%2ofilm\%2ois\%20\%E2\%80\%9Ctold\%E2\%80\%9D\%2C,the\%2ofirst\%2oand\%2othird\%2op erson.

Venditti, S., Piredda, F., \& Mattana, W. (2017). Micronarratives as the form of contemporary communication. The Design Journal, 2o(sup1), S273-S282. https://doi.org/10.1080/14606925.2017.1352804

R. Ramya is a Ph. D student in Department of English, School of Social Sciences and Languages at Vellore Institute of Technology, Vellore, India. Her research concerns the execution of narration in the new media.

Rukmini S. is a Senior Associate Professor of English in the School of Social Sciences and Languages at Vellore Institute of Technology, Vellore, India. She is interested in Indology, Aesthetics, Postcolonial studies and Digital Humanties. 